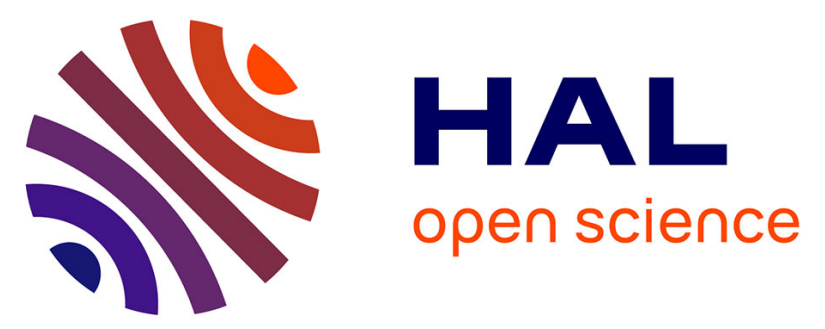

\title{
Investigations on the displacement damage dose effects induced by heavy ion irradiation in silicon PiN photodiodes: Implications for modeling and simulation
} Jonathan Riffaud, Marc Gaillardin, Mélanie Raine, Martial Martinez, Daniel Peyre, Claude Marcandella, Olivier Duhamel, Thierry Lagutère, Nicolas Richard, Philippe Paillet

\section{To cite this version:}

Jonathan Riffaud, Marc Gaillardin, Mélanie Raine, Martial Martinez, Daniel Peyre, et al.. Investigations on the displacement damage dose effects induced by heavy ion irradiation in silicon PiN photodiodes: Implications for modeling and simulation. Nuclear Instruments and Methods in Physics Research Section B: Beam Interactions with Materials and Atoms, 2019, 460, pp.52 - 55. 10.1016/j.nimb.2019.05.018 . hal-03488627

\section{HAL Id: hal-03488627 https://hal.science/hal-03488627}

Submitted on 21 Dec 2021

HAL is a multi-disciplinary open access archive for the deposit and dissemination of scientific research documents, whether they are published or not. The documents may come from teaching and research institutions in France or abroad, or from public or private research centers.
L'archive ouverte pluridisciplinaire HAL, est destinée au dépôt et à la diffusion de documents scientifiques de niveau recherche, publiés ou non, émanant des établissements d'enseignement et de recherche français ou étrangers, des laboratoires publics ou privés.

\section{다)(1) $(5$}

Distributed under a Creative Commons Attribution - NonCommerciall 4.0 International 


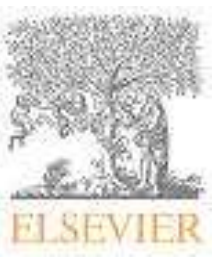

NUCLEAR INSTRUMENTS

\& METHODS

IN PHYSICS

RESEARCH

Section B

\title{
Investigations on the displacement damage dose effects induced by heavy ion irradiation in silicon PiN photodiodes: implications for modeling and simulation
}

Jonathan Riffaud, Marc Gaillardin, Mélanie Raine, Martial Martinez, Daniel Peyre, Claude Marcandella, Olivier Duhamel, Thierry Lagutère, Nicolas Richard, Philippe Paillet

CEA, DAM, DIF, F-91257 Arpajon, France"

\begin{abstract}
In this paper, the displacement damage dose effects in PiN photodiodes is investigated using heavy ions experiments and numerical simulations realized thanks to Technology Computer Aided Design (TCAD) calculations. The parameter of interest is the dark current $\mathrm{I}_{\text {DARK }}$ delivered by the photodiode which evolves during the heavy ions irradiation. The main goal is to define a model which bridges the gap between the introduction of traps energy states localized in the Si bandgap and the electrical behavior (as dark current variation).
\end{abstract}

Keywords: Displacement damage dose; dark current; photodiode PiN; traps energy levels; heavy ions irradiation."

\section{Introduction}

Displacement Damage Dose (DDD) effects induced by irradiation (neutron, proton or heavy ion) in semiconductor materials and devices are widely studied since many years [1-3]. DDD can lead to generation and recombination or trapping phenomena [4-6] and modifies the electrical response of electronic devices. Several works are focused on the DDD effects in image sensors in particular for the space applications [7-9].

Shockley et al [10], has proposed an analytical modeling of electrical phenomena in silicon (SRH model). It is widely used in Technology Computer Aided Design (TCAD) in order to simulate the electrical behavior of silicon devices. This model can be adapted for different applications fields. Recently, a multi-scale simulation approach has been proposed to model the DDD effects in Si-based devices. Indeed, the methodology is based on the simulation of the DDD mechanisms from the particle interaction with the silicon until the impact on the device electrical response. This paper focuses on the SRH model adaptations in order to bridge the gap between the device electrical response (current-voltage characteristic) and the physical phenomena induced by irradiation.

The main objective of this study is to model the displacement damage dose effects in a PiN photodiode irradiated by heavy ions. To do that, electrical simulations including displacement damage dose effects are performed using models which take into account the behaviour of the semiconductor material at the microscopic scale. The dark current 
$\mathrm{I}_{\text {DARK }}$ evolution is taken as the parameter of interest to describe DDD effects induced by heavy ions irradiation [11-12]. In the first part, PiN photodiode, experimental facilities and numerical details are briefly presented.

Then, results of $\mathrm{I}_{\mathrm{DARK}}$ calculations using modified SRH model are compared to experimental results of $\mathrm{I}_{\text {DARK. }}$. They are expressed as a function of major parameters such as ion fluence $\Phi$ and DDD which is the product of Non Ionizing Energy Loss (NIEL) and particle fluence.

Those results are used to discuss whether or not the modified SRH model is suitable for DDD modelling and simulation.

\section{Experimental facilities and numerical details}

\subsection{Device under test: PiN photodiode}

PiN photodiodes are used to study the DDD effects induced by heavy ions irradiation in silicon. Photodiodes are composed of bulk silicon, the top and the bottom being doped to create $\mathrm{P}^{+}$and $\mathrm{N}^{+}$ regions. The large intrinsic area $(385 \mu \mathrm{m}$ depth $)$ is chosen to ensure that the heavy ions lose their whole energy in this intrinsic area. The different geometrical and doping parameters are described in the Figure 1.

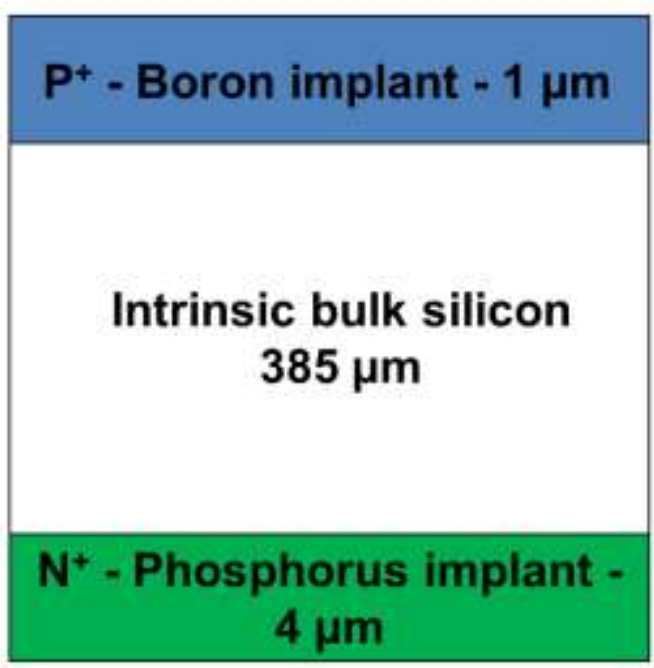

Figure 1: Schematic vertical cross section of a PiN photodiode used for experiments and simulations.

\subsection{Heavy ions experiments}

Heavy ion irradiations are performed thanks to two facilities as first, the Grand Accélérateur National d'Ions Lourds (GANIL, France). The other facility is RADiation Effect Facility (RADEF) located at Jyvaskyla, Finland. Major characteristics of used heavy ions are detailed in the table 1 . All irradiations are realized under vacuum at ambient temperature and in a total obscurity (PiN photodiodes are photosensitive sensors). Devices Under Test (DUT) are irradiated using normal incidence.

\begin{tabular}{ccccc}
\hline Heavy ions & Facility & $\begin{array}{c}\text { NIEL } \\
\left(\mathrm{MeV} . \mathrm{cm}^{2} / \mathrm{mg}\right)\end{array}$ & $\begin{array}{c}\text { Energy } \\
\text { per nucleon } \\
(\mathrm{MeV} / \mathrm{amu})\end{array}$ & $\begin{array}{c}\text { Range } \\
(\mu \mathrm{m})\end{array}$ \\
\hline $\mathrm{Xe}$ & GANIL & $0.98 \times 10^{-1}$ & 4 & 43 \\
$\mathrm{Ne}$ & GANIL & $1.39 \times 10^{-3}$ & 13 & 246 \\
$\mathrm{O}$ & GANIL & $8,97.10^{-4}$ & 13 & 299 \\
$\mathrm{Xe}$ & RADEF & $4.91 \times 10^{-2}$ & 9.3 & 89 \\
$\mathrm{Kr}$ & RADEF & $2.21 \times 10^{-2}$ & 9.3 & 94 \\
$\mathrm{Ne}$ & RADEF & $1.88 \times 10^{-3}$ & 9.3 & 146 \\
$\mathrm{~N}$ & RADEF & $9.45 \times 10^{-4}$ & 9.3 & 203 \\
\hline
\end{tabular}

Table 1: Characteristics of heavy ions used for irradiations

To characterize the electrical behavior of $\mathrm{PiN}$ photodiodes, experimental current-voltage I-V characteristics are acquired using a source measure unit in order to study both the forward and reverse electrical characteristics. The dark current measurement obtained in reverse mode for $\mathrm{V}_{\text {cathode }}=-10 \mathrm{~V}$ corresponds to the dark current $\mathrm{I}_{\text {DARK. }}$

PiN diodes have also been irradiated up to more than 1 MGy using $\mathrm{x}$-rays to get their response to ionizing radiation only. This has no significant influence on their electrical response. This means that any modification induced by heavy ions can be attributed to the displacement damage dose rather than to total ionizing dose effects.

\subsection{Numerical details}

Synopsys Sentaurus Technology Computer Aided Design (TCAD) tools are used to propose an 
approach to model and to simulate DDD effects in PiN photodiodes. The Shockley-Read-Hall model usually used to account for generation/recombination is used and modified in order to describe the impact of DDD phenomena induced by heavy ions irradiation which occur in bulk silicon. The intent is to model in a more physical manner the impact of displacement damage dose effect in silicon instead of simply modify the minority carrier lifetime $\tau$. Here, our approach is to use the minority carrier lifetime modification only for the initial calibration step presented in the section 3.1. Then, the SRH model is modified introducing discrete energy levels of traps called $\mathrm{E}_{\mathrm{TRAP}}$ in the $\mathrm{Si}$ bandgap. After the first calibration step, only the electrically active charge generation centers density $\mathrm{N}_{\text {TRAP }}$ is adjustable vs the particle fluence to simulate the irradiated device response.

\section{Simulation of the PiN photodiodes dark current evolution}

\subsection{Calibration of the 3D simulated PiN structure}

First of all, the first step is to calibrate the electrical response of the simulated device and compare it to an experimental I-V characteristic obtained on an unirradiated PiN photodiode (Figure 2). An experimental I-V characteristic is acquired with a polarization voltage from $1 \mathrm{~V}$ to $10 \mathrm{~V}$ (blue curve). For $0 \mathrm{~V}<\mathrm{V}_{\mathrm{p}}<1 \mathrm{~V}$, it is forward working mode and from $-10 \mathrm{~V}<\mathrm{V}<0 \mathrm{~V}$, it is reverse working mode, which is our mode of interest. The measured dark (reverse) current $\mathrm{I}_{\text {DARK }}$ is due to the remaining charge carrier generation.

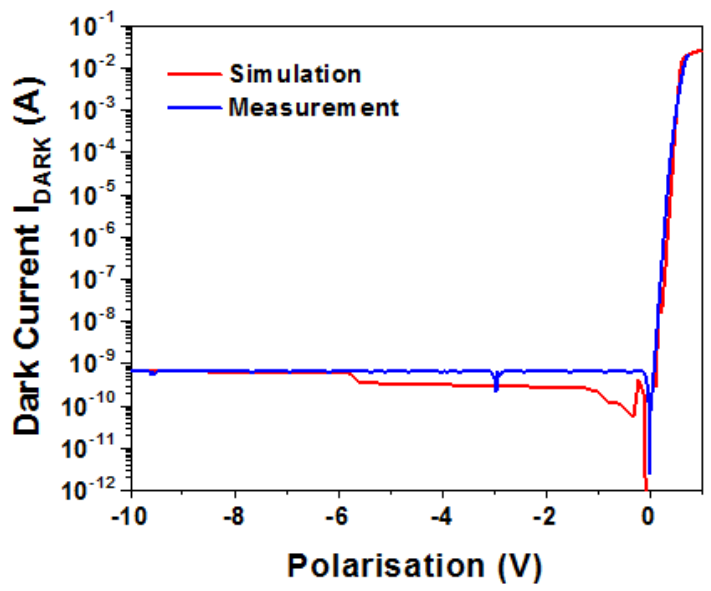

Figure 2: Calibration step of the PiN photodiode's electrical response with measurement (blue line) and simulated response (red line). Data are in good agreement.

Then, the real 3D geometry is generated using Synopsys Sentaurus software. The doping type and profile are precisely reproduced. A simulated I-V curve is computed using the minority carrier lifetime $\tau$ adjustment as in [13] in order to adjust the simulated I-V curve much as possible as the experimental data. As seen in the figure 2, results of calibration compared to experimental data are in good agreement.

\subsection{Simulation of DDD induced generation current in PiN photodiodes}

The impact of the DDD on the electrical response of Si-based devices is studied using the SRH model with the introduction of discrete traps energy levels $\mathrm{E}_{\mathrm{TRAP}}$ in Si bandgap with a fixed $\mathrm{N}_{\mathrm{TRAP}}$ density which are related to defects created in intrinsic area after heavy ions irradiation.

In the literature, such defects energies are generally considered as midgap defects so close to $0.55 \mathrm{eV}$ from the valence band. In a first approach, we have performed systematic simulation with $\mathrm{E}_{\mathrm{TRAP}}$ from $0.1 \mathrm{eV}$ to midgap $(0.5 \mathrm{eV})$, to study its influence on the device electrical response (Figure 3).

Figure 3 represents $I_{\text {DARK }}$ variation as a function of $\mathrm{N}_{\text {TRAP }}$ defects density. $\mathrm{E}_{\mathrm{TRAP}}$ levels are considered from the valence band, i.e $\mathrm{E}_{\mathrm{TRAP}}=0.1 \mathrm{eV}$ corresponds to $\mathrm{E}_{\mathrm{TRAP}}$ level of $0.1 \mathrm{eV}$ above the valence band). For $0 \mathrm{eV}<\mathrm{E}_{\mathrm{TRAP}}<0.1 \mathrm{eV}$ (black and 
red curves), $\mathrm{I}_{\text {DARK }}$ is constant (and at its minimum about $\mathrm{I}_{\mathrm{DARK}}=1 \mathrm{nA}$ whatever the defects density. Indeed, the generation centers are too far from the conduction band to significantly contribute to $\mathrm{I}_{\mathrm{DARK}}$ increase.

By contrast, for $\mathrm{E}_{\mathrm{TRAP}}>0.3 \mathrm{eV}$, the defects density begins to play a major. From $\mathrm{E}_{\mathrm{TRAP}}=0.35 \mathrm{eV}$, the generation rate becomes sufficiently high to significantly contribute to $\mathrm{I}_{\mathrm{DARK}}$ increase. Its evolution becomes linear closer as midgap $\mathrm{E}_{\mathrm{TRAP}}$. $\mathrm{N}_{\text {TRAP }}$ density increase leads to an $\mathrm{I}_{\text {DARK }}$ increase. For $\mathrm{E}_{\mathrm{TRAP}}$ values very close to midgap $\left(\mathrm{E}_{\mathrm{TRAP}}=0.45 \mathrm{eV}\right.$ and $\mathrm{E}_{\mathrm{TRAP}}=0.5 \mathrm{eV}$ ), the dark current is high even for the lower defects density $\left(\mathrm{N}_{\mathrm{TRAP}}=1.10^{15} \mathrm{~cm}^{-3}\right)$ as expected thanks to the enhanced probability for the charge carrier to reach the conduction band from the valence band. This result is expected because of the great probability for a generation center to give an electron towards the conduction band.

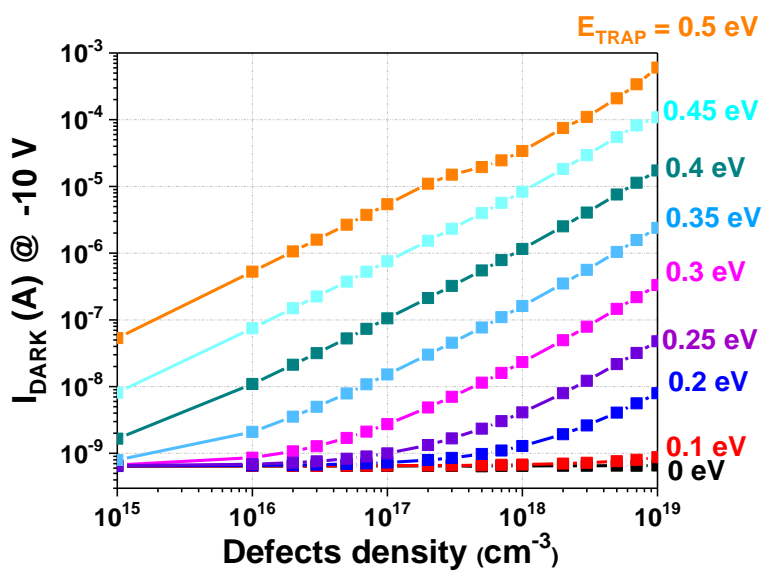

Figure 3: Results of simulation of dark current $\mathrm{I}_{\text {DARK }}$ as a function of defects density realized thanks to TCAD Synopsys Sentaurus. Each curve corresponds to energy of traps

\subsection{Experimental results}

The experimental $\mathrm{I}_{\text {DARK }}$ data obtained after heavy ions irradiation (performed at GANIL and RADEF) are now investigated. Figure 4 shows the $I_{\text {DARK }}$ evolution as a function of the ion fluence $\Phi$ for the irradiations with $\mathrm{Ne}$ and $\mathrm{Xe}$ ions (the other results being between these boudaries). We choose to show only the results obtained with the ions with "extreme NIEL" for clarity since the others show similar behaviors between these extreme curves. A continuous increase of $\mathrm{I}_{\text {DARK }}$ vs fluence is still observed for the three ions. This great increase is due to the generation defects increase in silicon. It can be noticed that the same value of dark current (e.g $\mathrm{I}_{\text {DARK }} \approx 1 \mathrm{nA}$ ) is obtained with a low fluence value, $\Phi=1.10^{5} \mathrm{~cm}^{-2}$ for $\mathrm{Xe}$ ions whereas for $\mathrm{Ne}$ ions the fluence is about $\Phi=1.10^{8} \mathrm{~cm}^{-2}$. This great difference is due to the NIEL of Ne ions which is about hundred times lower than $\mathrm{Xe}$ ions $\left(\mathrm{NIEL}_{\mathrm{NE}}=1.39 \times 10^{-3}\right.$ $\mathrm{MeV} . \mathrm{cm}^{2} / \mathrm{mg}$ and NIEL $\mathrm{XE}=0.98 \times 10^{-1} \mathrm{MeV} . \mathrm{cm}^{2} / \mathrm{mg}$ ). The deposited energy is strongly higher for Xe ions, which lead to a faster increase of the defects density in bulk silicon,.

By contrast, for $\mathrm{Ne}$ ions, despite their lower dark current values due to a reduced energy deposition (because of its weak NIEL), the evolution is linear and in constant increase. For a higher fluence than $\Phi=7.10^{11} \mathrm{~cm}^{-2}$, it can be reasonably expected that the $I_{\text {DARK }}$ value will reach its higher value. The same saturation phenomenon will probably occur. This phenomenon can be probably attributed to a saturation of the number of charge generation centers created in the bulk silicon.

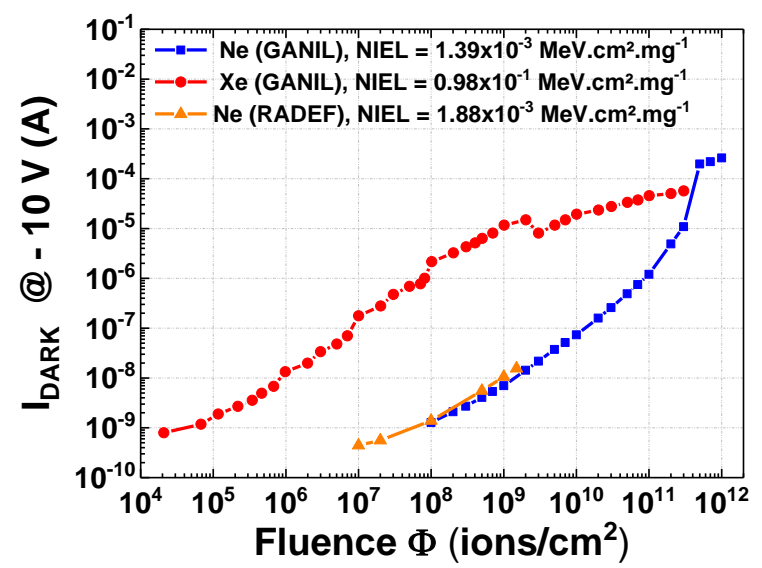

Figure 4: Experimental $\mathrm{I}_{\mathrm{DARK}}$ values as a function of fluence for $\mathrm{Ne}$ ions (13 MeV/n, blue curve and $9.3 \mathrm{MeV} / \mathrm{n}$, orange curve) and $\mathrm{Xe}$ ions (4 MeV/n, red curve).

In this paper, the displacement damage dose at the

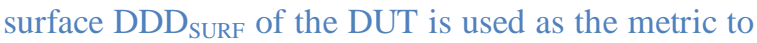
compare the dark current evolutions of the PiN diode 
with heavy ion irradiation. DDD SURF $_{\text {metric is used as }}$ the heavy ion LET at the entrance location of the DUT for radiation tests of electronic parts, for instance for space applications. Figure 5 represents $\mathrm{I}_{\text {DARK }}$ evolution as a function of displacement damage dose DDD $_{\text {SURF }}$ for the same two ions using the Non

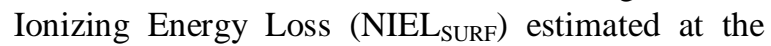
surface thanks to SRIM calculations [14].

$$
\mathrm{DDD}=\int_{n}^{\text {range }} \Phi \cdot \operatorname{NIEL}(\mathrm{x}) \cdot \mathrm{dx}
$$

Here, we can notice a linear increase of $\mathrm{I}_{\text {DARK }}$ with DDD $_{\text {SURF }}$ for the two ions. As expected, the same value of dark current is reached for lower DDD $_{\text {SURF }}$ value for $\mathrm{Xe}$ ions than for $\mathrm{Ne}$ ions. It can be explained with the NIEL and the penetration depth of $\mathrm{Xe}$ ions. Indeed, Xe ions range is weak, the damage dose is deposited close to the surface. The created defects are very localized and are probably mainly defects clusters. By contrast, for $\mathrm{Ne}$ ions which are lighter than Xe ions, the defects are created all along their paths, with a majority in depth in the intrinsic silicon area (at about $246 \mu \mathrm{m}$ from the surface). It is probably mainly point defects with a reduced clusters defects density. The displacement damage dose is distributed and that is why the dark current increase is slower (excepted for high fluence, where the defects density becomes very significant). Thus, another metric should be used to compare all the experimental results. The cumulated DDD in the intrinsic silicon area is chosen. It takes into account the evolution of NIEL and fluence versus the penetration depth since it sums the DDD versus the depth.

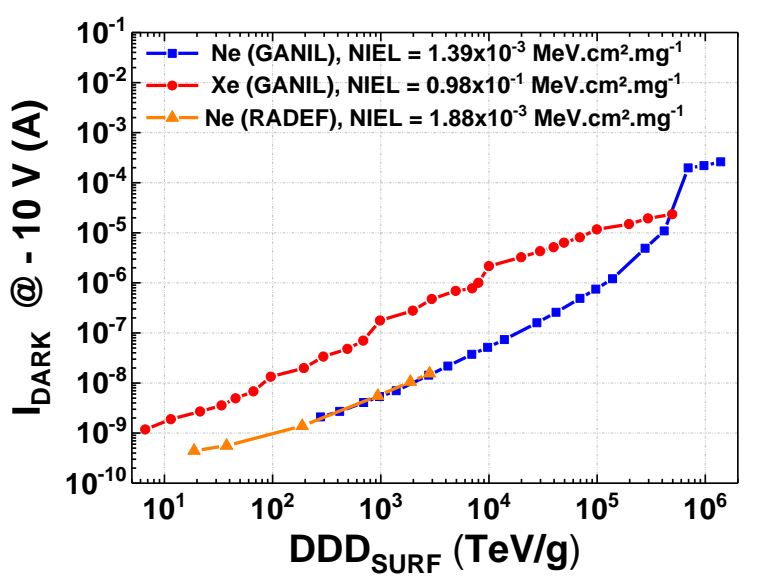

Figure 5: Experimental $\mathrm{I}_{\text {DARK }}$ values as a function of $\mathrm{DDD}_{\text {SURF }}$ for $\mathrm{Ne}$ ions (13 MeV/amu, blue curve and $9.3 \mathrm{MeV} / \mathrm{amu}$, orange curve) and $\mathrm{Xe}$ ions (4 MeV/amu, red curve).

To confirm our explanations, Figure 6 represents the total displacement damage dose as a function of the penetration depth in the bulk-Si photodiode. The maximum range estimated by SRIM calculations for $\mathrm{Xe}$ ions is about $44.5 \mu \mathrm{m}$. The reached total displacement damage dose is about $\mathrm{DDD}_{\mathrm{MAX}, \mathrm{Xe}}=1686 \mathrm{TeV} / \mathrm{g}$ (SRIM calculations) at the end of their paths. A maximum of defects are created (probably mainly clusters defects because of the great DDD values) near the surface of the photodiodes. By contrast, for $\mathrm{Ne}$ ions, the range is significantly greater, about $246 \mu \mathrm{m}$ with a total DDD of about $\mathrm{DDD}_{\mathrm{MAX}, \mathrm{Ne}}=90 \mathrm{TeV} / \mathrm{g}$ which is widely lower than for Xe ions, according to SRIM calculations. The total deposited non-ionizing dose is relatively low all along the path of the Ne ions. Small and punctual defects are mainly created. These results explain why the dark current increase is quicker for Xe ions, the density and size of the created defects leading to a higher charge carrier generation rate. 


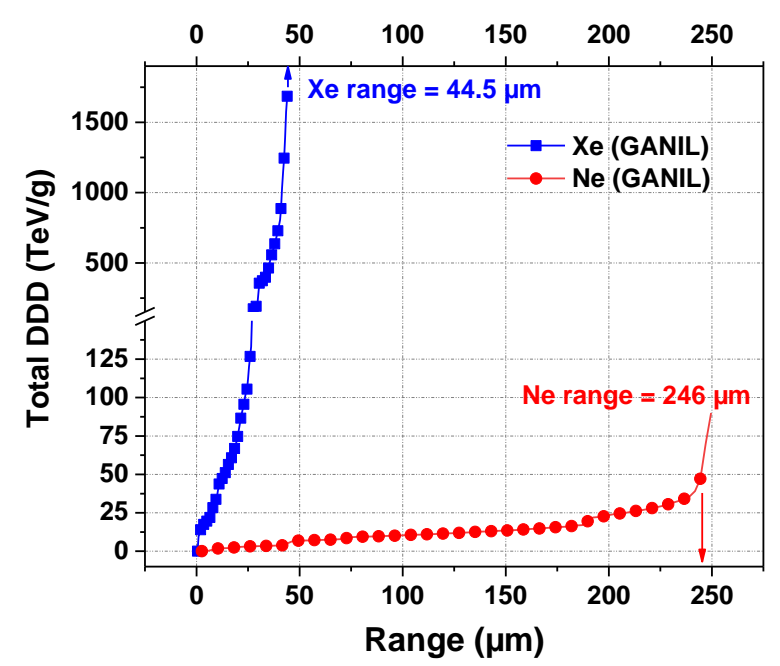

Figure 6: Total displacement damage dose as a function of penetration depth for Xe ions (blue curve) and Ne ions (red curve).

In order to compare to our $\mathrm{I}_{\mathrm{DARK}}$ experimental data (Figure 5), simulations shown in Figure 3 are used. As seen on the literature [15-17], $\mathrm{E}_{\mathrm{TRAP}}$ is commonly located near the midgap $\left(\mathrm{E}_{\mathrm{TRAP}} \approx 0.5 \mathrm{eV}\right)$ and determined by Deep Level Transient Spectroscopy (DLTS) or Thermally Stimulated Current (TSC) methods for example. So, the simulated data of the dark current generated at $\mathrm{V}_{\mathrm{P}}=-10 \mathrm{~V}$ as a function of $\mathrm{N}_{\text {TRAP }}$ are used with $\mathrm{E}_{\mathrm{TRAP}}=0.45 \mathrm{eV}$ and $\mathrm{E}_{\mathrm{TRAP}}=0.5 \mathrm{eV}$ (dashed and dash dotted curves). $\mathrm{N}_{\text {TRAP }}$ becomes the only parameter which evolves.

A linear evolution of $I_{\text {DARK }}$ is observed for both $\mathrm{E}_{\mathrm{TRAP}}$ values (green curves). For comparison, the red curve corresponds to experimental data of dark current from an irradiation performed at GANIL with $\mathrm{Xe}$ ions $(4 \mathrm{MeV} / \mathrm{n})$ as a function of $\mathrm{DDD}_{\text {SURF. }} \mathrm{I}_{\mathrm{DARK}}$ evolves nearly linearly with the DDD $_{\text {SURF }}$ increase, its values are in the interval of the estimated values from the simulation. Charge generation centres seem to have an energy close to $\mathrm{E}_{\mathrm{TRAP}}=0.45 \mathrm{eV}$. An increase of one decade for the defects density seems to lead to an increase of one decade for $\mathrm{I}_{\text {DARK }}$ value.

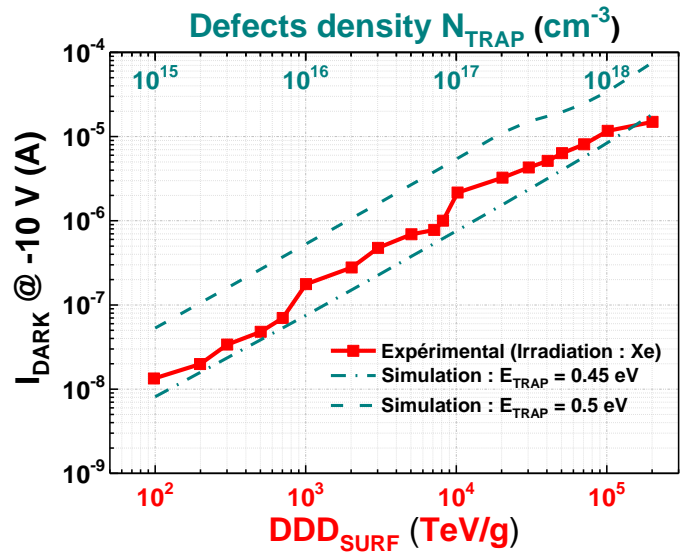

Figure 7: Comparison between experimental $\mathrm{I}_{\text {DARK }}$ values as a function of $\mathrm{DDD}_{\mathrm{SURF}}$ for $\mathrm{Xe}$ ions $(4 \mathrm{MeV} / \mathrm{n}$, red curve) and estimated $\mathrm{I}_{\text {DARK }}$ values as a function of defects density $\mathrm{N}_{\text {TRAP }}$ for two values of $\mathrm{E}_{\mathrm{TRAP}}$.

The comparison of $\mathrm{I}_{\mathrm{DARK}}$ values from simulation and experimental data seems follow the same evolution, so it can be expected that the introduced energy traps levels in the simulation can describe with accuracy what is happens during heavy ions irradiation.

\section{Conclusion}

In this paper, heavy ions experiments and TCAD model based on Shockley Read Hall theory is used to describe the DDD effects and electrical behavior modifications occurring in a $\mathrm{PiN}$ photodiode. This model is modified with the introduction of energy levels in the Si bandgap to simulate the DDD effects after heavy ions irradiations. It allows us to perform simulations more realistic than a simple modification of the minority carrier lifetime $\tau$. Indeed, $\tau$ can be expressed as a function of the defects density $\mathrm{N}_{\text {TRAP }}$ and capture cross section $\sigma_{\mathrm{n}, \mathrm{p}}$. Here, only $\mathrm{N}_{\mathrm{TRAP}}$ is a variable parameter. Moreover, energy traps are, here, discrete levels. More simulations will be performed with different shapes of traps levels (Gaussian or exponential) in order to be closer of the real physical phenomena which occur. The first results have shown good agreement between the $\mathrm{I}_{\text {DARK }}$ experimental and simulated data. The model will be improved with different values of the minority carrier capture cross section in next future. Then, active pixel sensor (APS) could be used as DUT in the future to do 
statistics (very high number of pixels) because each pixel contains a PiN photodiode and the DDD effects easily identified in the acquired picture. Finally, this model will be applied and adapted to other electronic components as bipolar transistor.

\section{References}

[1] J. Srour et al, NSREC short course, 1988

[2] J. Srour et al, IEEE Trans on Nucl. Sci, vol 50, n³, 2003.

[3] J. Srour, IEEE Trans on Nucl. Sci, vol 53, nº, 2006.

[4] J. Srour, IEEE Trans on Nucl. Sci, vol 60, n³, 2013.

[5] T.R Oldham, NSREC short course, 2011

[6] H.J Barnaby, NSREC short course, 2005

[7] C. Virmontois, IEEE Trans on Nucl. Sci, vol 59, nº 6,2012

[8] J. Bogaerts, IEEE Trans on Elec. Dev, 2003

[9] C. Virmontois, , IEEE Trans on Nucl. Sci, vol 58, n6, 2011

[10] W;Shockley, Phys Rev ,37, 835;1952

[11] S.R Messenger, IEEE Trans on Nucl. Sci, vol 46, n6, 1999

[12] J. Srour et al, IEEE Trans on Nucl. Sci, vol 47, $\mathrm{n}^{\circ} 6,2000$.

[13] D.K Schroder, book, chap 7, 2006

[14] SRIM (Online) Available http://www.srim.org

[15] I.V Antonova et al, IEEE Trans on Nucl. Sci, vol 51, n³, 2004

[16] D. Kindl et al, ASDAM Conference, 2008.

[17] J . Sewaniratne et al, IEEE Trans on Nucl. Sci, 2009. 